\title{
The gene encoding P27 lipoprotein and a putative antibiotic-resistance gene form an operon in Mycobacterium tuberculosis and Mycobacterium bovis
}

\author{
F. Bigi, ${ }^{1}$ A. Alito, ${ }^{2}$ M. I. Romano, ${ }^{1}$ M. Zumarraga, ${ }^{1}$ K. Caimi ${ }^{1}$ \\ and A. Cataldi ${ }^{1}$ \\ Author for correspondence: A. Cataldi. Tel: +54 114621 0199. Fax: +54 1144812975. \\ e-mail: acataldi@inta.gov.ar
}

Instituto de Biotecnología ${ }^{1}$ and Instituto de Patobiología², CICV-INTA, PO Box 77, Castelar, Argentina

\begin{abstract}
P27 is an antigenic membrane lipoprotein synthesized by members of the Mycobacterium tuberculosis complex. Northern blotting and RT-PCR experiments indicated that the genes encoding P27 and a putative antibiotic transporter (P55) form an operon. A promoter region was identified and characterized by deletion analysis in Mycobacterium smegmatis. Two transcription initiation points were mapped in Mycobacterium bovis BCG by primer extension analysis to 76 bp and 87 bp upstream of the ATG initiation codon. Putative $\mathbf{- 1 0}$ and $\mathbf{- 3 5}$ promoter consensus sequences associated with these showed $66 \%$ similarity to previously identified mycobacterial promoters. These results suggest that the P27IP55 operon is transcribed from two promoters in $M$. bovis BCG.
\end{abstract}

Keywords: Mycobacterium tuberculosis, Mycobacterium bovis, promoter, operon, lipoprotein

\section{INTRODUCTION}

The identification and characterization of mycobacterial antigenic proteins are essential for the development of new diagnostic tests and vaccines, and for the understanding of the pathogenic mechanisms of mycobacteria and the immune responses to them. Numerous mycobacterial antigens have been described (Young et al., 1992); many of them have been expressed in Escherichia coli and their recognition by immune cells and antibodies determined. However, little is known concerning their cellular function in mycobacteria. Gene expression regulation studies may help to understand their physiological function, but there is slow progress in this field. Only a few mycobacterial promoters have been studied (Bashyam et al., 1996; Mulder et al., 1997), and many of these are from phage or antibiotic-resistance genes, which might not be similar to the genes involved in virulence. In addition, most mycobacterial promoters described seem to be different from the E. coli consensus -10 and -35 elements (Dale \& Patki, 1990). Also, little is known about to what extent mycobacterial genes form parts of operons. Some operons have been experimentally demonstrated (Papavinassasundaram et al., 1997; Berthet et al., 1998), but most were postulated based on nucleotide sequence examination (Braibant et al., 1996a, b; DeMaio et al., 1997; Cole et al., 1998).

P27 is a novel Mycobacterium bovis antigen, identified from an expression library using sera from naturally infected cattle (Bigi et al., 1997). Sequence analysis indicated that P27 has a characteristic signal sequence for lipoprotein modification (a signal peptidase type II site). Cellular fractionation experiments suggested that P27 is an integral membrane protein. Downstream of the $P 27$ gene there is an ORF for a $55 \mathrm{kDa}$ protein (P55) which is highly homologous to membrane proteins related to antibiotic resistance in Streptomyces and other bacteria. These genes seem to be organized as an operon, because only six bases separate the end of the P27 gene from the start of the P55 gene. The present study demonstrates the polycistronic nature of both genes, as well as the location of the promoter.

\section{METHODS}

Bacterial strains, and growth and electroporation conditions. All cloning steps were performed in E. coli DH5 $\alpha$. Expression studies were done in Mycobacterium smegmatis $\mathrm{mc}^{2} 155$. Cultures of E. coli were grown in LB broth or on LB agar. For the promoter deletion experiments, M. smegmatis cells were 
Table 1. Plasmids used in the present study

\begin{tabular}{|c|c|c|}
\hline Plasmid & Characteristics* & Reference \\
\hline pBluescript II SK & $\mathrm{Ap}^{\mathrm{r}}$, IPTG-inducible E. coli expression vector & Stratagene \\
\hline pMBA21 & $\begin{array}{l}\mathrm{Ap}^{\mathrm{r}}, 2 \cdot 0 \mathrm{~kb} \text { EaeI fragment of M. bovis AN5 DNA } \\
\text { in pBluescript II SK, containing P27 and part of } \\
\text { P55 }\end{array}$ & Bigi et al. (1997) \\
\hline pGEM-5Zf $(+)$ & $\mathrm{Ap}^{\mathrm{r}}$, E. coli cloning vector & Promega \\
\hline pGEM-T & $\mathrm{Ap}^{\mathrm{r}}, \mathrm{PCR}$ products $E$. coli cloning vector & Promega \\
\hline $\mathrm{pP} 27 \mathrm{G}$ & $\begin{array}{l}\mathrm{Ap}^{\mathrm{r}}, 1.5 \mathrm{~kb} \text { Sacl fragment from pMBA21 cloned } \\
\text { into pGEM-5Zf }(+)\end{array}$ & Present study \\
\hline pSUM39/41 & $\mathrm{Km}^{\mathrm{r}}$, shuttle cloning vectors & Aínsa et al. (1996) \\
\hline pMBA27 & $\begin{array}{l}\mathrm{Km}^{\mathrm{r}}, 1 \cdot 2 \mathrm{~kb} \text { PstI fragment from pP27G inserted in } \\
\text { pSUM39 }\end{array}$ & Present study \\
\hline pGdir27 & $\begin{array}{l}\text { Ap }{ }^{\mathrm{r}}, 2-1 \mathrm{Dir} / 2-1 \mathrm{Av} 3 \text { PCR fragment cloned into } \\
\text { pGEM-T }\end{array}$ & Present study \\
\hline pG292 & $\begin{array}{l}\text { Ap }^{r}, \text { U292/2-1Av3 PCR fragment cloned into } \\
\text { pGEM-T }\end{array}$ & Present study \\
\hline pG241 & $\begin{array}{l}\text { Ap }^{r}, \text { U241/2-1Av3 PCR fragment cloned into } \\
\text { pGEM-T }\end{array}$ & Present study \\
\hline $\mathrm{pMBA} 27 \Delta \mathrm{P}$ & $\begin{array}{l}\mathrm{Km}^{\mathrm{r}}, 1 \cdot 011 \mathrm{~kb} \text { PstI fragment from pGdir27 } \\
\text { inserted in pSUM41 }\end{array}$ & Present study \\
\hline pMBA2792 & $\begin{array}{l}\mathrm{Km}^{\mathrm{r}}, 1 \cdot 093 \mathrm{~kb} \text { PstI fragment from pG292 inserted } \\
\text { in pSUM41 }\end{array}$ & Present study \\
\hline pMBA2741 & $\begin{array}{l}\mathrm{Km}^{\mathrm{r}}, 1 \cdot 144 \mathrm{~kb} \text { Pst I fragment from pG241 inserted } \\
\text { in pSUM41 }\end{array}$ & Present study \\
\hline pHP45 & $\mathrm{Ap}^{\mathrm{r}} / \mathrm{Sm}^{\mathrm{r}}$, cloning vector & Prentki \& Krisch (1984) \\
\hline pMBA2792 $\Omega$ & $\begin{array}{l}\mathrm{Km}^{\mathrm{r}} / \mathrm{Sm}^{\mathrm{r}}, 2 \mathrm{~kb} \text { HindIII fragment from } \mathrm{pHP} 45 \\
\text { inserted in pMBA2792 }\end{array}$ & Present study \\
\hline pMV261 & $\mathrm{Km}^{\mathrm{r}}$, mycobacterial expression vector & Stover et al. (1991) \\
\hline pMBA28 & 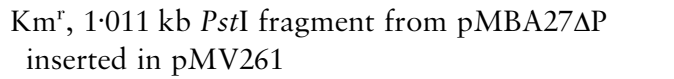 & Present study \\
\hline
\end{tabular}

*Ap ${ }^{\mathrm{r}}$, resistance to ampicillin; $\mathrm{Km}^{\mathrm{r}}$, resistance to kanamycin; $\mathrm{Sm}^{\mathrm{r}}$, resistance to streptomycin.

grown to late-exponential phase at $37^{\circ} \mathrm{C}$, either in liquid or on solid LB medium and in Middlebrook 7H11 medium supplemented with OADC (albumin, dextrose, catalase and oleic acid; Difco). When necessary, appropriate antibiotics were added at the following concentrations: ampicillin, $100 \mu \mathrm{g}$ $\mathrm{ml}^{-1}$; streptomycin, $10 \mu \mathrm{g} \mathrm{ml}^{-1}$; kanamycin, $50 \mu \mathrm{g} \mathrm{ml}{ }^{-1}$ for $E$. coli or $20 \mu \mathrm{g} \mathrm{ml}^{-1}$ for M. smegmatis. M. bovis BCG Pasteur $\mathrm{P} 1732$ was grown to saturation in Middlebrook $7 \mathrm{H} 9 / 0 \cdot 05 \%$ Tween 80 supplemented with OADC (M7H9-OADC-Tw). Then, $2 \mathrm{ml}$ culture was transferred to $100 \mathrm{ml}$ M7H9-OADCTw broth and cultured further for $10 \mathrm{~d}$. Mycobacterial strains were electroporated using the method of Wards \& Collins (1996). Electroporations were performed using a Bio-Rad Gene Pulser. For use in transformation, M. smegmatis $\mathrm{mc}^{2} 155$ was grown to mid-exponential phase in M7H9-OADC-Tw. Following electroporation, M. smegmatis was cultured on Middlebrook 7H11 medium supplemented with OADC and containing antibiotic.

DNA manipulations. Standard methods were used for restriction-endonuclease digestion of plasmids, DNA ligations, Southern blotting, and other manipulations (Ausubel et al., 1996). Plasmid DNA isolation was performed using a Wizard Minipreps SV kit, according to the manufacturer's instructions (Promega). DNA probes for Southern blot hybridization were labelled with $\left[\alpha^{32} \mathrm{P}\right] \mathrm{CTP}$ using the
Oligolabelling random priming kit according to the manufacturer's instructions (Pharmacia).

Mycobacterial DNA preparation. DNA from M. bovis and M. smegmatis was prepared according to van Soolingen et al. (1991).

Plasmid constructions. Plasmids used are described in Table 1. A $1.5 \mathrm{~kb} \mathrm{SacI}$ fragment was obtained by digestion of pMBA21 and cloned into SacI-linearized pGEM-5Zf (Promega), generating pP27G. A $1.2 \mathrm{~kb}$ Pst I fragment of pP27G, corresponding to the $5^{\prime}$ non-coding region followed by the sequence encoding P27, was cloned into the PstI-digested pSUM39 shuttle vector. The resulting plasmid was named pMBA27.

To obtain plasmids carrying different deletions in the $5^{\prime}$ noncoding sequences of the P27 gene, four DNA fragments containing the P27 gene plus different DNA extensions upstream of the ATG start codon were obtained by PCR, using chromosomal DNA from M. bovis BCG as template and the 2-1Av3 primer in combination with the 2-1Dir, U292 and U241 primers (Table 2). The PCR products were cloned into the pGEM-T plasmid (Promega), generating pGdir27, pG292 and pG241, respectively. Subsequently, the PstI fragments obtained by digestion of pGdir27, pG292 and pG241 were cloned in the Pst I site of pSUM41 vector, generating pMBA27 $\mathrm{P}$, pMBA2792 and pMBA2741, respectively. In parallel, pHP45 was digested with HindIII to isolate the 
Table 2. Oligonucleotide primers

\begin{tabular}{|llc|}
\hline Primer & \multicolumn{1}{|c|}{ DNA sequence } & $\begin{array}{c}\text { Relative } \\
\text { position to } \\
\text { P27 start } \\
\text { codon (nt) }\end{array}$ \\
\hline 2-1Dir & 5'-cctcacagacaccctctacg-3' $^{\prime}$ & -28 \\
2-1Av3 & 5'-tgcgctgcaccacaaatc-3' $^{\prime}$ & 1116 \\
2-1Av4 & $5^{\prime}$-gtgacgatccaggtgatcc-3' & 870 \\
U292 & $5^{\prime}$-cgttcctcaacaattccg-3' & -110 \\
U241 & $5^{\prime}$-atggtcagccgcgccgca-3' & -160 \\
L358P27 & $5^{\prime}$-tgagttggccggtcggcgag-3' & -25 \\
2-1Rev & $5^{\prime}$-tcaaccagcgtcaccatcag-3' & 1589 \\
\hline
\end{tabular}

streptomycin-resistance gene $(2 \cdot 0 \mathrm{~kb})$, which was subsequently ligated into HindIII-linearized pMBA2792. This plasmid was called pMBA2792 $\Omega$. The PstI fragment from pMBA27 $\Delta \mathrm{P}$ was subcloned into the unique PstI site of pMV261, downstream of the hsp60 promoter. The resulting plasmid was named pMBA28.

PCR amplification and sequencing. Primers used are listed in Table 2.

PCR amplification was performed with Taq DNA polymerase (Promega) under standard conditions in a volume of $50 \mu \mathrm{l}$. The concentration of dNTPs was $0.2 \mathrm{mM}$ each, and $20 \mathrm{pmol}$ of each primer was used. Cycling conditions were: one cycle of $95^{\circ} \mathrm{C}$ for $2 \mathrm{~min}$, followed by 35 cycles of $94^{\circ} \mathrm{C}$ for $1 \mathrm{~min}$, $49{ }^{\circ} \mathrm{C}$ (for $2-1 \mathrm{Av} 3 / \mathrm{U} 292$ primer set), $53{ }^{\circ} \mathrm{C}$ (for $2-1 \mathrm{Av} 3 / \mathrm{U} 241$ primer set) or $54{ }^{\circ} \mathrm{C}$ (for 2-1Av3/2-1Dir primer set) for $1 \mathrm{~min}$, $72{ }^{\circ} \mathrm{C}$ for $1 \mathrm{~min}$, and finally $72^{\circ} \mathrm{C}$ for $10 \mathrm{~min}$. A total of $0 \cdot 1 \mathrm{ng}$ plasmid or 2 ng genomic M. bovis DNA was used as template. Sequencing was performed by PCR-mediated Taq-cycle sequencing using the fmol sequencing kit (Promega) according to the manufacturer's instructions. Sequencing products were developed on $6 \%$ polyacrylamide gels

RNA preparation. Total RNA from $M$. bovis BCG and $M$. smegmatis was isolated following the method of Bashyam et al. (1996). The two rRNA species and a band of lower molecular mass, corresponding to tRNA, were visible after staining agarose gels with ethidium bromide, indicating that the RNA preparations were of high integrity.

Northern blotting. RNA samples were run on $0.8 \%$ agarose gels containing $2 \cdot 2 \mathrm{M}$ formaldehyde (Ausubel et al., 1996), and transferred by vacuum in $10 \times$ SSC $(3 \mathrm{M} \mathrm{NaCl}, 0 \cdot 3 \mathrm{M}$ sodium citrate) to a nylon membrane. RNA was fixed to the membrane by UV light cross-linking. Membranes were pre-hybridized for $3 \mathrm{~h}$ in $500 \mathrm{mM}$ sodium phosphate $(\mathrm{pH} 7 \cdot 2) / 7 \%$ SDS at $55^{\circ} \mathrm{C}$. Hybridization was performed as described by Harth et al. (1996) in the same buffer at $55^{\circ} \mathrm{C}$ for $48 \mathrm{~h}$ with an antisense oligonucleotide (L358P27) labelled with $\left[\gamma^{32} \mathrm{P}\right] \mathrm{ATP}$ at $10^{8}$ c.p.m. $\mu \mathrm{g}^{-1}$. Membranes were then washed three to five times with $50 \mathrm{mM}$ sodium phosphate $(\mathrm{pH} 7 \cdot 2) / 0 \cdot 1 \%$ SDS, and exposed to Kodak X-ray film (Biomax MR) at $-70{ }^{\circ} \mathrm{C}$.

Primer extension. Primer extension was performed using the L358P27 primer. Ten picomoles of the non-phosphorylated primer was labelled with T4 polynucleotide kinase (Promega) in the presence of $\left[\gamma_{-}{ }^{32} \mathrm{P}\right]$ ATP. RNA $(6 \mu \mathrm{g})$ and the labelled primer $(0 \cdot 1 \mathrm{pmol})$ were mixed in a volume of $7 \mu$ l containing $50 \mathrm{mM}$ Tris/ $\mathrm{HCl}(\mathrm{pH} 8 \cdot 3$ ) and $0 \cdot 1 \mathrm{M} \mathrm{KCl}$. The reaction was then incubated for $1 \mathrm{~min}$ at $94^{\circ} \mathrm{C}, 10 \mathrm{~min}$ at $55^{\circ} \mathrm{C}$ and $15 \mathrm{~min}$ on ice. The volume of the mixture was adjusted to $12 \mu \mathrm{l}$ by the addition of $1 \mu \mathrm{l}$ of a mixture containing dNTPs $(2.5 \mathrm{mM}$ each), $0 \cdot 5 \mu \mathrm{l}$ RNAsin (Promega), $2 \cdot 2 \mu \mathrm{l}$ reverse transcriptase $5 \times$ buffer $(0.25 \mathrm{M}$ Tris $/ \mathrm{HCl}, \mathrm{pH} 8.3 ; 0.2 \mathrm{M} \mathrm{KCl} ; 36 \mathrm{mM}$ magnesium acetate, $0.01 \mathrm{M}$ DTT), $0.8 \mu \mathrm{l}$ diethylpyrocarbonate-treated water and $0.5 \mu$ avian myeloblastosis virus reverse transcriptase (RT; Promega). Reverse transcription was performed at $42{ }^{\circ} \mathrm{C}$ for $45 \mathrm{~min}$ and stopped by addition of $5 \mu \mathrm{l}$ stop buffer.

Samples were electrophoresed in a $6 \%$ polyacrylamide gel containing $8 \mathrm{M}$ urea alongside the sequencing products obtained with the same oligonucleotide primer. Gels were fixed in $5 \%(\mathrm{v} / \mathrm{v})$ methanol $/ 5 \%(\mathrm{v} / \mathrm{v})$ acetic acid, and exposed to X-ray film (Kodak X-Omat RS) for $24 \mathrm{~h}$ at $-70{ }^{\circ} \mathrm{C}$.

RT-PCR. Synthesis of the first strand of cDNA was performed using $3 \mu \mathrm{g}$ total M. bovis BCG RNA as template and random hexamers as primers, following the indications in the 'SUPERScript Preamplification System for First Strand cDNA Synthesis' kit (Life Technologies). Ribonuclease-treated RNA samples were used as a negative control. A $5 \mu \mathrm{l}$ aliquot of the cDNA synthesis reaction was amplified with primers 21Dir/2-1Av4 and 2-1Dir/2-1Rev. Amplification conditions were denaturation at $94^{\circ} \mathrm{C}$ for $2 \mathrm{~min}$, followed by 30 cycles at $94^{\circ} \mathrm{C}$ for $1 \mathrm{~min}, 55^{\circ} \mathrm{C}$ for $1 \mathrm{~min}$ and $72^{\circ} \mathrm{C}$ for $1 \mathrm{~min}$. Amplification products were detected in $1 \%$ agarose gels. The specificity of the amplified bands was determined by Southern blotting using $\left[\alpha^{-32} \mathrm{P}\right] \mathrm{dCTP}$ pMBA21 as probe.

SDS-PAGE and Western blotting. Cells were harvested by centrifugation, washed and resuspended in PBS buffer, and lysed by boiling in loading buffer (2\% SDS; $0 \cdot 125 \mathrm{M}$ Tris/ $\mathrm{HCl}, \mathrm{pH} 6.8 ; 1 \%$ 2-mercaptoethanol; $0.02 \%$ bromophenol blue; $10 \%$ glycerol) for $10 \mathrm{~min}$. Proteins $(50 \mu \mathrm{g})$ were separated by electrophoresis in $15 \%$ SDS-PAGE gels by the technique of Laemmli (1970), and electrotransferred onto nitrocellulose using a Bio-Rad Trans-Blot Cell tank transfer unit at $150 \mathrm{~mA}$ for $2 \mathrm{~h}$ in $25 \mathrm{mM}$ Tris $/ \mathrm{HCl}$ (pH 8.0), $0.19 \mathrm{M}$ glycine and $20 \%(\mathrm{v} / \mathrm{v})$ methanol. Transfer yield was visualized by transient staining with Ponceau Rouge. Non-specific sites in the blot were blocked by incubation for $1 \mathrm{~h}$ with $5 \%$ dried non-fat powdered milk in $20 \mathrm{mM}$ Tris $/ \mathrm{HCl}(\mathrm{pH} 7 \cdot 5), 0.5 \mathrm{M}$ $\mathrm{NaCl}$ buffer (TBS) at room temperature. Nitrocellulose membranes were incubated overnight at $4{ }^{\circ} \mathrm{C}$ with a $1: 300$ dilution of anti-P27 polyclonal serum followed by an alkalinephosphatase-conjugated secondary antibody for $2 \mathrm{~h}$ at room temperature. Colour reaction was developed for $30 \mathrm{~min}$ by the addition of 5-bromo-4-chloro-3-indolyl phosphate and toluidinum nitro blue tetrazolium as substrates.

\section{RESULTS}

\section{Determination of the transcription initiation point}

The start point of P27 transcription was determined based on the primer extension assay using total M. bovis BCG RNA treated with DNase. An antisense primer whose $5^{\prime}$ end corresponds to the nucleotide -25 relative to the $\mathrm{A}$ in the start codon was used. This reaction yielded two products, a larger one (P1), with a weaker signal consistent with a start at the A situated at $87 \mathrm{nt}$ from the start codon, and a shorter product (P2), with the stronger signal, and corresponding to the most likely transcription start point, mapping to a $G 76 \mathrm{nt}$ upstream of the start codon (Fig. 1a, lane 2; Fig. 1b). However, the possibility that these extension products may result from a transcriptional stop of the reverse transcriptase in the assay due to RNA secondary structures cannot be 
(a)

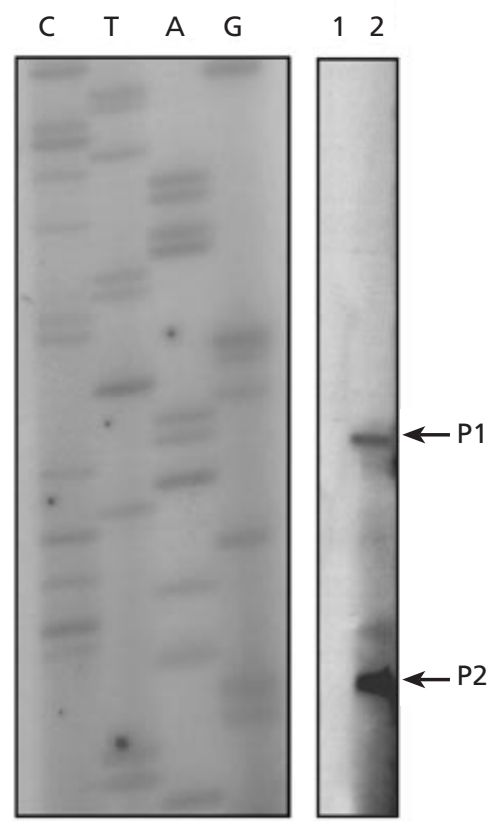

(b)

GTGGCGTCCACATGTCCCTGCACGATGTGCCCGCCGAGCCGGCTGCCCAGCGCCGCGGCGC GTTCCAGGTTCACCCGGCTGCCGGGCCGTAGCTCACCCAGGTTGGACCGGTTCAGTGTCTC GGCCATCACGTCGGCGGTGAATTGGCCGTCGGGCAATACATCGACGACCGTCAGACACACG CCGTTGACAGCGATCGAGTCGCCGTGGCCGGCGTCGGCGGTAACCATCGGACCGCGGATGG TCAGCCGCGCCGCATCGACCAGGGCCTCACGCCCGGTCACTTCTCCGC QTTCCTDAACAAT TCCGG GAACATCGCACCAGGTTAGGCAGCAATCCCGCGGACCCGCACCCCACTCGCCGAC CGGCCAACTCACAGACACCCTCTACGATGCAGGGT ATG CGG ACC

$M \quad R \quad T$

Fig. 1. Determination of transcriptional start points for the $P 27$ gene. (a) Primer extension reactions were carried out with endlabelled L358P27 primer annealing at nucleotide position -25 relative to the $A$ residue of the initiation codon of the $P 27$ gene. This primer was then annealed to total RNA isolated from $M$. bovis BCG, and extended with reverse transcriptase. Reactions were analysed on urea- $6 \%$ gels. Sequencing reactions were performed with the same oligonucleotide on pMBA21 and run alongside the primer extension reaction. Primer extension reactions were carried out in the presence (lane 1) or absence (lane 2) of ribonuclease $\left(20 \mu \mathrm{g} \mathrm{ml}^{-1}\right)$. (b) Genetic arrangement upstream from the $P 27$ gene. The transcriptional start points ( $P 1$ and $P 2$ ) are indicated; the -35 consensus sequence is boxed and the -10 consensus sequence is boxed and underlined. The essential promoting region is shaded; the putative Shine-Dalgarno sequence is underlined; the ATG translational start codon is indicated in bold.

excluded. Primer extension reactions were repeated three times, and the same banding pattern was observed. Ribonuclease treatment abolished the observed extension product (Fig. 1, lane 1).

\section{$P 27$ and P55 genes are organized in an operon}

The close proximity of an ORF encoding P55 in the same transcriptional orientation downstream of the P27 gene suggests that the P27 and P55 genes form an operon. To investigate this possibility, Northern blot hybridization and RT-PCR reactions using total $M$. bovis BCG RNA were performed. For Northern blots, hybridizations were carried out using a specific radiolabelled antisense oligonucleotide probe, L358P27, which targets to nucleotide position -25 on the P27 mRNA relative to the ATG start codon. A single band, heavier than $2 \mathrm{~kb}$, was detected in M. bovis BCG RNA (Fig. 2a). The specificity of the oligonucleotide was demonstrated by the absence of detectable hybridization in total RNA from M. smegmatis. M. bovis BCG RNA treated with ribonuclease did not react, indicating that genomic DNA was not present. The possibility of crosshybridization of the P27 probe to the rRNA species was excluded by stripping the blot and rehybridizing with a $16 \mathrm{~S}$ rRNA gene of Bacillus subtilis. RNA bands (one band of $1.5 \mathrm{~kb}$ for the small rRNA; and a weakly crossreactive band of $3.2 \mathrm{~kb}$ for the large rRNA) showed different molecular masses than those observed with the P27 probe (Fig. 2b). All samples were previously treated with DNases to avoid hybridization to DNA. Thus the P27 mRNA transcript size is consistent with polycistronic transcription.

For RT-PCR assays, a population of cDNA was obtained by the use of a hexanucleotide mix in the retrotranscription reaction of $M$. bovis BCG RNA (treated with DNase), which was used in a second step as template in PCR reactions. Two combinations of primers were used for the amplification reaction: 21Dir/2-1Av4 and 2-1Dir/2-1Rev. See Fig. 2(d) for the position of each primer. RT-PCR produced amplification products of the expected size for polycistronic mRNA $(1.617 \mathrm{~kb}$ with the primers 2-1Dir/2-1Rev and 898 bp with the primers 2-1Dir/2-1Av4) (Fig. 2c). The fidelity of the reaction was confirmed by Southern blotting using pMBA21 as a probe (data not shown). In ribonuclease-treated RNA samples no bands were observed in agarose gels or by Southern blotting, excluding the possibility that the products were amplified from genomic sequences.

\section{Deletion analysis of the $\mathbf{P} \mathbf{2 7}$ gene promoter}

In order to map the P27 gene promoter, deletion derivatives of the $5^{\prime}$ non-coding region were generated. Four DNA fragments containing the P27 gene plus different-sized DNA extensions (410, 161, 110 and $28 \mathrm{bp}$ ) of the $5^{\prime}$ non-coding region were amplified by PCR and inserted into the pSUM41 vector. The resulting plasmids were named pMBA27, pMBA2741, pMBA2792 and pMBA27 $\triangle \mathrm{P}$. All these constructions were introduced by electroporation into M. smegmatis $\mathrm{mc}^{2} 155$. P27 expression was assessed in cell extracts by Western blotting using an anti-P27 serum (Fig. 3). P27 expression was detected in M. smegmatis/pMBA27, M. smegmatis/ pMBA2741 and M. smegmatis/pMBA2792 strains, while none was observed in M. smegmatis/pSUM41 and M. smegmatis/pMBA27 $\Delta \mathrm{P}$ (Fig. 3, lanes 1-5). To discard the possibility that the plac promoter of the pSUM vector drives P27 gene transcription, a transcription terminator was added to the construction 
(a)

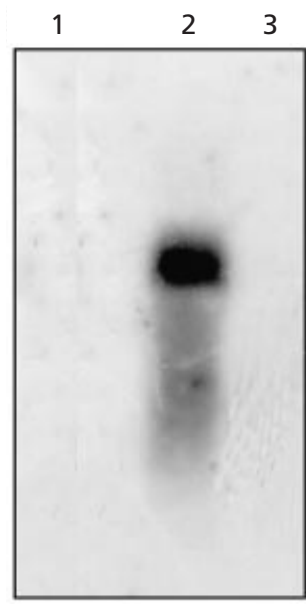

(b)

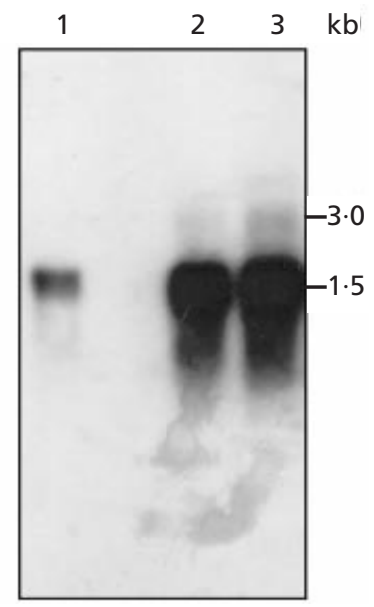

(c)

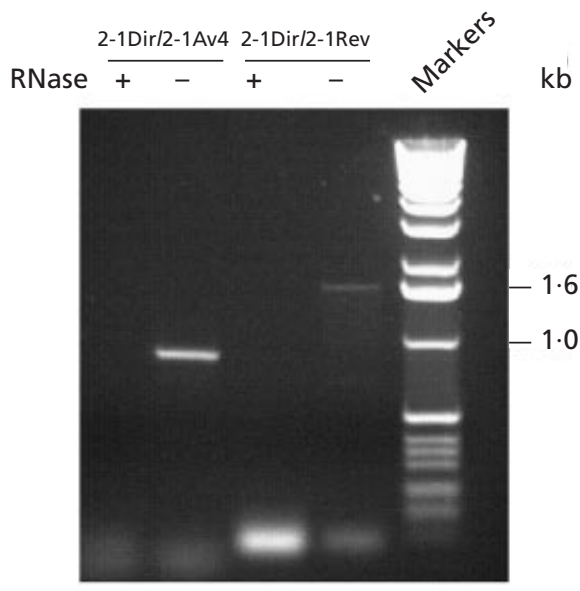

(d)

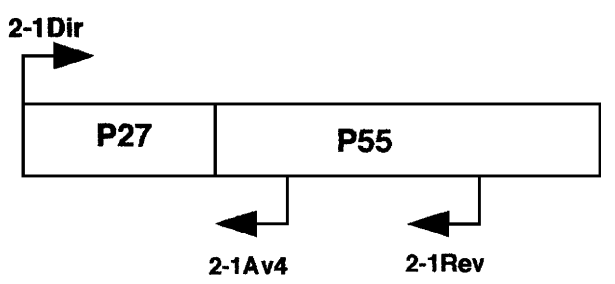

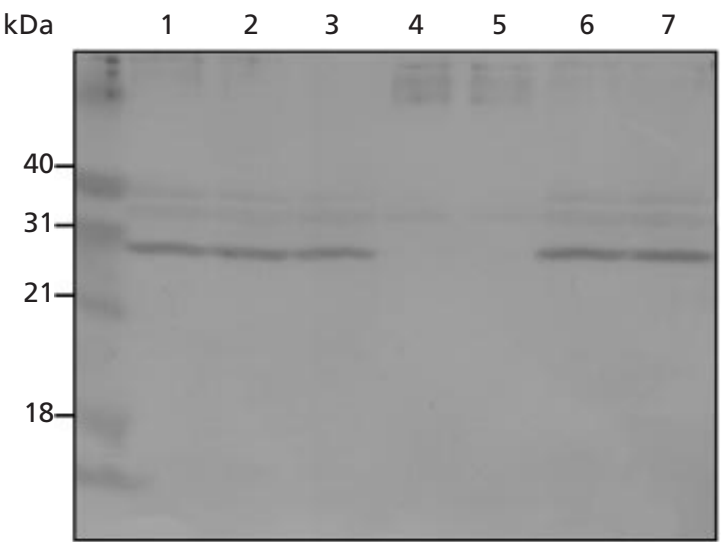

Fig. 3. Western blot of cell extracts from $M$. smegmatis clones carrying deletions of the $5^{\prime}$ non-coding region of P27. Lanes: 1, M. smegmatis/pMBA27; 2, M. smegmatis/pMBA2741; 3, M. smegmatis/pMBA2792; 4, M. smegmatis/pMBA27 $\Delta \mathrm{P}$; 5, M. smegmatis/pSUM41; 6, M. smegmatis/pMBA2792 2 ; 7, $M$. smegmatis/pMBA28. The lanes were incubated with anti-P27 polyclonal serum.

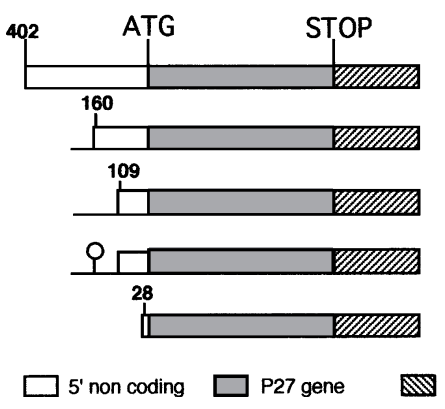

P27 EXPRESSION

Fig. 4. Determination of promoter activity of the $5^{\prime}$ non-coding region in $M$. smegmatis. Genetic elements are indicated. The stem-loop indicates a possible transcriptional terminator. Plasmids harbouring different $5^{\prime}$ non-coding deletions were obtained by cloning of PCR amplification products into pSUM41. Expression of the P27 recombinant protein is indicated.

an $\Omega$ fragment into DNA leads to termination of RNA synthesis in M. smegmatis (Timm et al., 1994). In this study, P27 expression was detected in M. smegmatis/ pMBA2792 (Fig. 3, lane 6). To test the integrity of the $P 27$ gene in the shorter insert (that showing no expression), the P27 coding sequence in the pMBA27 $\Delta \mathrm{P}$ plasmid was subcloned downstream of the $h s p 60$ promoter into the pMV261 vector, to give the pMBA28 plasmid. P27 expression was observed in $M$. smegmatis/pMBA28 (Fig. 3, lane 7), confirming that the insert has a potentially functional gene.

Deletion analysis showed that a sequence important for promoter activity lay between 28 and 110 nt upstream of the start codon (Fig. 4). Analysis of the region upstream of transcriptional start point $\mathrm{P} 2$ revealed two potential -10 hexamers, one (GAACAT) 8 bp upstream which carrying the minimal promoter region. The omega $(\Omega)$ interposon was cloned into the plasmid pMBA2792 downstream of the plac promoter, resulting in plasmid pMBA2792 $\Omega$. It has been demonstrated that insertion of 
has $3 / 6$ matches with the typical E. coli -10 consensus sequence (TATAAT), 4/6 matches with the mycobacterial superoxide dismutase gene promoter (GATTAT) (Zhang et al., 1991) and 4/6 matches with the promoter of a gene encoding the $38 \mathrm{kDa}$ protein of Mycobacterium tuberculosis (GAAATT) (Andersen \& Hansen, 1989), and another (CATCGC) 5 bp upstream of the transcription start point which has $4 / 6$ matches with the -10 promoter sequence of the $m p b 70$ gene (CATCAG) (Matsuo et al., 1995). In addition, we found a -35 hexamer positioned at $26 \mathrm{nt}$ from the transcription start point which has $4 / 6$ matches with the -35 consensus sequence of the $h s p 60$ promoter of $M$. bovis BCG (TTGCAC) (Shinnick, 1987; Thole et al., 1987).

However, at $7 \mathrm{bp}$ upstream of the longer extension product (P1) there is an AACAAT motif that matches five of six positions of the -10 (AAGAAT) promoter sequence of the hsp60 gene of M. bovis BCG. Around the corresponding -35 position, we identified several potential consensus sequences which are homologous to published promoter sequences of $M$. bovis and $M$. tuberculosis. However, these -35 elements are outside of the minimal promoting region as determined by the deletion experiment, indicating that they are not essential to the transcription of the P27 gene under the culture conditions used in this study.

\section{DISCUSSION}

To study the expression and transcriptional features of the $P 27$ gene, we characterized its $5^{\prime}$ non-coding region. We mapped the P27 gene promoter region by the progressive $5^{\prime}$ deletion of the putative regulatory sequence. Our results revealed that there is a minimal promoter region between bases -28 and -110 relative to the start codon. We defined this promoter region as an essential sequence to transcribe the P27 gene under the culture conditions used in this work. Two possible transcription initiation points were identified, but only one (P2), which maps 76 bases upstream of the proposed ATG initiation codon, had associated potential promoter sequences placed in the minimal region with promoter activity. Probably, a second promoter (P1) is localized in the deleted region. Operons with more than one promoter have been described in mycobacteria which are active under different physiological conditions (Suzuki et al., 1991; Movahedzadeh et al., 1997; Verma et al., 1999). It could be possible that the P1 promoter is dominant under other conditions and the promoter region may be dynamic depending on the growth conditions.

The recognition of promoter sequences in prokaryotes is mainly mediated by the $\sigma$ subunit of RNA polymerase. In most bacteria, these promoters are constituted by hexamers placed in positions -10 and -35 or in their vicinity. In E. coli, the -10 and -35 consensus sequences and the distance that separates them have been extensively studied. However, this information is not directly applicable to M. tuberculosis or M. bovis, because, in general, mycobacterial promoters function poorly in E. coli, indicating that mycobacteria may possess different transcriptional signals. Despite their importance as microbial pathogens and heterologous expression systems, little is known about the structure of mycobacterial gene promoters. Several promoters were predicted by either computer analysis or their distances from experimentally determined transcription start points, using conventional E. coli promoter spacing and sequences as a guideline, but only in some cases was promoter activity experimentally confirmed. The low homology among the promoter sequences reported makes the establishment of a specific consensus sequence for mycobacterial promoters difficult. However, a number of mycobacterial consensus sequences have been proposed. Bashyam et al. (1996) used mycobacterial promoter sequences isolated from M. tuberculosis and M. smegmatis to generate the following probable consensus sequence for the -10 region: T $(100 \%)$, A ( $93 \%)$, T $(50 \%)$, A $(57 \%)$, a $(43 \%)$ and T $(71 \%)$ for $M$. smegmatis and T $(80 \%)$, A $(90 \%)$, Y $(60 \%)$, g $(40 \%)$, A $(60 \%)$ and T $(100 \%)$ for M. tuberculosis. However, they were unable to find a single strongly conserved sequence in the -35 regions. Using all the putative mycobacterial sequences published, Mulder et al. (1997) calculated the mycobacterial promoter consensus sequence as follows: -35 : T $(92 \%), \mathrm{T}(53 \%), \mathrm{G}(62 \%)$, A $(44 \%), \mathrm{C}(60 \%), \mathrm{G}(31 \%) / \mathrm{A}(26 \%)$; and -10 : T $(68 \%)$, A $(76 \%), \mathrm{T}(41 \%)$, A $(36 \%) / \mathrm{G}(26 \%)$, A $(34 \%) / C(28 \%)$, T $(76 \%)$. During analysis of the $5^{\prime}$ untranslated $P 27$ gene region two overlapping putative -10 (GAACAT, CATCGC) sequences were identified. The GAACAT -10 hexamer proposed conserves the second and the last two positions on the Mulder et al. (1997) consensus. We also identified a putative -35 sequence (TTCCTC) which shares $66 \%$ identity with other mycobacterial promoters. Other putative promoters were described in our previous paper (Bigi et al., 1997). However, these potential promoters as well as the -35 element associated with transcriptional start point $\mathrm{P} 1$ are outside the essential promoting region. The future characterization and mapping of the $\mathrm{P} 2$ promoter are necessary to understand the regulation mechanisms of $P 27 / P 55$ operon transcription. It is possible that the promoters are recognized by different RNA polymerase holoenzymes, and they are utilized to different extents during growth.

The spacing between the putative -10 and -35 regions is in agreement with other mycobacterial promoters reported. It has been demonstrated that the mycobacterial promoter can accommodate a large variety of sequences between the -35 and -10 regions. Such an analysis was performed by Kremer et al. (1995), who observed that the distances from $4 \mathrm{bp}$ to $64 \mathrm{bp}$ are functional in the $85 \mathrm{~A}$ promoter.

Since the mapping of the P27 gene promoter was performed in M. smegmatis for reasons of convenience, it would be important to confirm these results in a native producer species (M. bovis and M. tuberculosis). However, Bashyam et al. (1996) suggested that the basic 
transcriptional machineries of $M$. smegmatis and $M$. tuberculosis have transcriptional specificity determinants in common. Thus M. smegmatis can be safely used as a surrogate host for expression of at least the constitutively expressed genes from slowly growing pathogenic mycobacteria.

The proximity of an ORF downstream of the $P 27$ gene led us to suppose the existence of a polycistronic messenger which would be the transcription product of both genes. Although polycistronic messengers are often found in prokaryotes, to our knowledge only a few mRNAs of this type have been identified in M. bovis, e.g. ESAT-6 antigen, which was found to be encoded in a transcriptional unit formed by two genes (Berthet et al., 1998). Many more polycistronic transcripts should exist in M. bovis and M. tuberculosis, since analysis of the genome sequence of $M$. tuberculosis (Cole et al., 1998) allows the identification of various potential operons. Using Northern blotting and RT-PCR assays, we demonstrated that P27 and a gene encoding a putative antibiotic transporter (P55) belong to the same transcriptional unit. Such a genetic organization suggests that a functional relationship exists between the products of both genes. The search for the role of this operon in M. bovis is currently under way.

Interestingly, three putative membrane proteins from M. tuberculosis, LprA, LprF and LppX (accession nos Z77137, Z81011 and Z83858, respectively), share high homology with P27. The ORFs encoding these three proteins as well as the P27 version of M. tuberculosis ( $\operatorname{lpr} G$; accession no. Z80108) were identified during the M. tuberculosis genome sequencing project (Cole et al., 1998) but in contrast to the P27 gene, they are not adjacent to genes encoding drug transporters and do not seem to be organized in an operon-like structure. Immunoblot studies indicated that P27 shares epitopes with LprA (data not shown). The function of P27 and these related sequences is not known, but the close identity suggests that they may belong to a novel membrane antigenic protein family.

Future studies will help determine whether this conserved sequence reflects a similarity in cellular function of these proteins.

\section{ACKNOWLEDGEMENTS}

This work was supported by the Centro Argentino Brasileño de Biotecnología (CABBIO) and the Programa de Cooperacion Hispano-Argentina. We thank Haydee Gil for technical help. The valuable suggestions of Cecilia Vazquez Rovere are gratefully acknowledged.

F.B., M.I.R. and A.C. are fellows of the National Research Council of Argentina (CONICET). K.C. is the recipient of a CONICET fellowship.

\section{REFERENCES}

Aínsa, J. A., Martín, M., Cabeza, M., De la Cruz, F. \& Mendiola, M. V. (1996). Construction of a family of Mycobacterium/ Escherichia coli shuttle vectors derived from pAL5000 and
pACYC184: their use for cloning an antibiotic-resistance gene from Mycobacterium fortuitum. Gene 176, 23-26.

Andersen, A. B. \& Hansen, E. B. (1989). Structure and mapping of antigenic domains of protein antigen $\mathrm{b}$, a 38,000-molecular weight protein of Mycobacterium tuberculosis. Infect Immun 57, 2481-2488.

Ausubel, F. M., Brent, R., Kingston, R. E., Moore, D. D., Seidman, J. G., Smith, J. A. \& Struhl, K. (1996). Current Protocols in Molecular Biology. New York: Wiley.

Bashyam, M. D., Kaushal, D., Dasgupta, S. K. \& Tyagi, A. K. (1996). A study of the mycobacterial transcriptional apparatus: identification of novel features in promoter elements. J Bacteriol 178, 4847-4853.

Berthet, F.-X., Rasmussen, P. B., Rosenkrands, I., Andersen, P. \& Gicquel, B. (1998). A Mycobacterium tuberculosis operon encoding ESAT-6 and a novel low-molecular-mass culture filtrate protein (CPF-10). Microbiology 144, 3195-3203.

Bigi, F., Espitia, C., Alito, A., Zumarraga, M., Cravero, S. \& Cataldi, A. (1997). A novel $27 \mathrm{kDa}$ lipoprotein antigen from Mycobacterium bovis. Microbiology 143, 3599-3605.

Braibant, M., Lefevre, P., de Wit, L., Ooms, J., Peirs, P., Huygen, K., Wattiez, R. \& Content, J. (1996a). Identification of a second Mycobacterium tuberculosis gene cluster encoding proteins of an ABC phosphate transporter. FEBS Lett 394, 206-212.

Braibant, M., Lefevre, P., de Wit, L., Peirs, P., Ooms, J., Huygen, K., Andersen, A. B. \& Content, J. (1996b). A Mycobacterium tuberculosis gene cluster encoding proteins of a phosphate transporter homologous to the Escherichia coli Pst system. Gene 176, 171-176.

Cole, S. T., Brosch, R., Parkhill, J. \& 39 other authors (1998). Deciphering the biology of Mycobacterium tuberculosis from the complete genome sequence. Nature 393, 537-544.

Dale, J. W. \& Patki, A. (1990). Mycobacterial gene expression and regulation. In Molecular Biology of the Mycobacteria, pp. 172-189. Edited by J. McFadden. Guildford: Surrey University Press.

DeMaio, J., Zhang, Y., Ko, C. \& Bishai, W. R. (1997). Mycobacterium tuberculosis sigF is part of a gene cluster with similarities to the Bacillus subtilis sigF and sigB operons. Tuber Lung Disc 78, 3-12.

Harth, G., Lee, B. Y., Wang, J., Clemens, D. L. \& Horwitz, M. A. (1996). Novel insights into the genetics, biochemistry, and immunocytochemistry of the 30-kilodalton major extracellular protein of Mycobacterium tuberculosis. Infect Immun 64, 3038-3047.

Kremer, L., Baulard, A., Estaquier, J., Content, J., Capron, A. \& Locht, C. (1995). Analysis of the Mycobacterium tuberculosis 85A antigen promoter region. J Bacteriol 177, 642-653.

Laemmli, U. K. (1970). Cleavage of structural proteins during the assembly of the head of bacteriophage T4. Nature 227, 680-685.

Matsuo, T., Matsumoto, S., Ohara, N., Kitaura, H., Mizuno, A. \& Yamada, T. (1995). Differential transcription of the MPB70 genes in two major groups of Mycobacterium bovis BCG substrains. Microbiology 141, 1601-1607.

Movahedzadeh, F., Colston, M. J. \& Davis, E. O. (1997). Determination of DNA sequences required for regulated $\mathrm{Myco-}$ bacterium tuberculosis RecA expression in response to DNAdamaging agents suggests that two modes of regulation exist. $J$ Bacteriol 179, 3509-3518.

Mulder, M. A., Zappe, H. \& Steyn, L. M. (1997). Mycobacterial promoters. Tuber Lung Disc 78, 211-223.

Papavinassasundaram, K. G., Movahedzadeh, F., Keer, J. T., 
Stoker, N. G., Colston, M. J. \& Davis, E. O. (1997). Mycobacterial recA is cotranscribed with a potential regulatory gene called $r e c X$. Mol Microbiol 24, 141-153.

Prentki, P. \& Krisch, M. (1984). In vitro insertional mutagenesis with a selectable DNA fragment. Gene 29, 303-313.

Shinnick, T. M. (1987). The 65-kilodalton antigen of Mycobacterium tuberculosis. J Bacteriol 169, 1080-1088.

van Soolingen, D., Hermans, P. W. M., de Haas, P. E. W., Soll, D. R. \& van Embden, J. D. A. (1991). Occurrence and stability of insertion sequences in Mycobacterium tuberculosis complex strains: evaluation of an insertion sequence dependent DNA polymorphism as a tool in the epidemiology of tuberculosis. $J$ Clin Microbiol 29, 2578-2586.

Stover, C. K., de la Cruz, V. F., Fuerst, T. R. \& 11 other authors (1991). New use of BCG for recombinant vaccines. Nature 351, 456-460.

Suzuki, Y., Nagata, A. \& Yamada, T. (1991). Analysis of the promoter region in the rRNA operon from Mycobacterium bovis BCG. Antonie Leeuwenhoek 60, 7-11.

Thole, J. E., Keulen, W. J., Kolk, A. H., Groothuis, D. G., Berwald, L. G., Tiesjema, R. H. \& van Embden, J. D. (1987). Characterization, sequence determination, and immunogenicity of a 64 kilodalton protein of Mycobacterium bovis BCG expressed in Escherichia coli K-12. Infect Immun 55, 1466-1475.

Timm, J., Lim, E. M. \& Gicquel, B. (1994). Escherichia colimycobacteria shuttle vectors for operon and gene fusion to lacZ: the pJEM series. J Bacteriol 176, 6749-6753.

Verma, A., Sampla, A. K. \& Tyagi, J. S. (1999). Mycobacterium tuberculosis rrn promoters: differential usage and growth ratedependent control. J Bacteriol 181, 4326-4333.

Wards, B. J. \& Collins, D. M. (1996). Electroporation at elevated temperatures substantially improves transformation efficiency of slow-growing mycobacteria. FEMS Microbiol Lett 145, 101-105.

Young, D. B., Kaufmann, S. H. E., Hermans, P. W. M. \& Thole, J. E. R. (1992). Mycobacterial protein antigens: a compilation. Mol Microbiol 6, 133-145.

Zhang, Y., Lathigra, R., Garbe, T., Catty, D. \& Young, D. (1991). Genetic analysis of superoxide dismutase, the 23 kilodalton antigen of Mycobacterium tuberculosis. Mol Microbiol 5, 381-391.

Received 17 June 1999; revised 3 December 1999; accepted 20 December 1999. 